\title{
158 STRENGTH TRAINING EXERCISE FOR SPECIAL
} POPULATION

K Prabhakaran Manilal Scientific Officer, Sports Authority of India, Bangalore, Karnataka, India

\subsection{6/bjsm.2010.078725.158}

Development of an appropriate strength training programme for different population is a complicated process. This programme design requires a solid understanding of the underlying scientific principles and should be based on a sound rationale. For an effective strength training programme design, it is very important to identify the specific variables that need to be controlled in order to better predict the training outcomes. The proper combination of these variables will determine the type of exercise stimulus presented to the body because presentation of appropriate exercise stress is very vital for optimum physiological adaptation. Strength training exercise prescription for children, women and elderly people need special attention, as it should cater the training goal and individual need. 